\title{
Resistencias a la teoría y restos críticos: George Bataille y Maurice Blanchot en la Argentina de los 50
}

\author{
2. Verónica stedile Luna / Universidad Nacional de La Plata - CONICET \\ veronica.stedileluna@gmail.com
}

\section{Resumen}

«La moral de Henry Miller», de Bataille y «René Char", de Maurice Blanchot, publicados en I948 y 1953 respectivamente, en revistas literarias argentinas, constituyen episodios de resistencia a la teoría anteriores a la eclosión discursiva que caracterizará los modos de transacción entre crítica y teoría de la década del 50 en adelante. Este artículo aborda por un lado, un problema historiográfico, ¿cómo y dónde leer estos ensayos?, ¿es posible ubicarlos en algunas de las bibliotecas teóricas que influyeron en lo que se denominó «modernización de la crítica» a partir del grupo Contorno?; por otro lado, piensa la dimensión tropológica de estos ensayos cuyos procedimientos argumentativos se sustraen de una relación coincidente entre gramática y lógica, ya que exhiben un pensamiento de la paradoja y la indeterminación. Archivo de la crítica como perspectiva que se desplaza de la noción de historia de la crítica, y resistencia a la teoría, estas son las dos entradas que el artículo propone para pensar, finalmente, qué es posible volver a decir de nuestros propios recorridos de lectura y las luces o enigmas de una época.

Palabras clave: historiografía crítica • revistas literarias • resistencia a la teoría pensamiento de la paradoja

\begin{abstract}
«Henry Miller's moral», by Georges Bataille and «René Char», by Maurice Blanchot, published respectively at 1948 and 1953 in argentine literary magazines, can be considerate as episodes of "resistance to theory» previous to the discursive eclosion that characterized the manners of transaction between critics and theory from the I950s on wards. On the one hand, this paper thinks about a historiographic issue: how and where Bataille and Blanchot's essays were read? Is it possible to locatet hem in the kind of theory lectures that were influential for what was called "modernization of criticism", especially around the Contorno magazine and group? On the other hand, the paper analyzes the tropological dimension of these essays whose argumentative procedures are subtracted from a coincidental relationship between grammar and logic, as they display a paradoxical and indeterminate way of thinking. The most important question about these essays is why they could not be read by the argentine critic historiography, and what the study of this essays can enlight about this period of time.
\end{abstract}

Key words: literary magazines $\cdot$ critical historiography $•$ resistance to theory $\cdot$ paradox 
En 1948 la revista Ciclo tradujo para su primer número el ensayo «La moral de Henry Miller» de Georges Bataille, precedido por un extenso fragmento de Trópico de Capricornio. Cinco años después, Poesía Buenos Aires publicó un número monográfico dedicado a René Char, donde se incluía un ensayo de Maurice Blanchot (1953:II-I2) sobre Hojas de Hipnos. ${ }^{1}$ Tanto Ciclo como Poesía articularon deseos de renovación teórica en torno al arte moderno con la propuesta de una literatura invencionista, que no representara nada, «ni realidades, ni surrealidades» (Bayley). ${ }^{2}$ Esa apuesta teórica y literaria en pugna con una idea de mímesis motivó la traducción de estos textos, que a su vez intervenían en la polémica sobre el "compromiso literario», puesto de relieve a partir de Qu'est-ce que la littérature? (Sartre).

«La moral de Henry Miller» fue también el ensayo con el cual Bataille inició la publicación de Critique. Revue générale des publications françaises et étrangères (1946-195I), desde donde intervino en el debate con Les temps modernes, dirigida por Jean Paul Sartre. «René Char» es uno de los capítulos que integra La part du feu (1949), y allí también Blanchot pensaba las implicancias de una teoría como el existencialismo. ${ }^{3}$ Así, no es sorprendente que estos textos presenten coincidencias teóricas y filosóficas tales como la insumisión de la literatura respecto de los deberes morales/afirmativos de la comunicación, la imposibilidad de lo total como exigencia ética, la paradoja como forma de un pensamiento sobre la experiencia que no puede ser conceptualizada a la manera en que se relacionan gramática y lógica (De Man). Estos ensayos empujaban el lenguaje al borde de lo posible al desarrollar nociones como «poder del instante» o desasnar el peso cultural de la «inspiración» para pensar las paradojas y consecuencias de entrar en contacto con ella.

«La moral de Henry Miller», sobre Trópico de Cáncer, Trópico de Capricornio y Primavera Negra, permite a Bataille desplegar cuatro núcleos principales que continúan las obsesiones de Acéphale: política del instante como aniquilación de la conciencia; el rechazo de la acción como medida de lo que rinde; contradicción del azar; desacople entre infancia y humanidad — «nada tengo que ver con la maquinaria rechinante de la humanidad, ipertenezco a la tierra! Me lo digo con la cabeza hundida en la almohada, siento que brotan cuernos en mis sienes. jYo soy inhumano!», cita Bataille de Miller-.

El artículo de Maurice Blanchot sobre René Char plantea una insuficiencia de las historias de la literatura "para hablarnos de textos de los que toda manera hablar será insuficiente» (I953:s/n); revisa dos conceptos frecuentes en ellas, «inspiración» $\mathrm{y}$ «reflexión», que fallan por representar o bien un fruto de la ignorancia o un exceso de conciencia. Blanchot radicaliza ambos términos para señalar el poder de la anterioridad y la ausencia como condiciones del lenguaje. Esboza entonces algunas de las nociones principales de su teoría: el hecho de que la literatura supone un tipo específico de comunicación («nada más alejado del discurso que ella, y sin embargo admite sus recursos, admite articulaciones de la frase»); la idea de que la imagen, en el poema, no es aquello de lo que se puede tener clave (designación o ilustración de las cosas), sino «la ausencia de todo lo que ella 
nos da»; y un pensamiento paradójico de la relación entre poema y realidad: «el poema va hacia la ausencia para recomponer con ella la realidad total». Así como para Bataille el instante supone un «anonadamiento sin límites» y por tanto la destrucción de todas las cosas ordenadas, el poema, para Blanchot no reconoce el reposo porque no reposa sobre nada, «se rehúsa a todas fuerzas de la sumisión» que serían incluso el sueño como recurso a la escritura automática (inspiración), ${ }^{4}$ el compromiso como mensaje (reflexión), en suma, la tranquilidad de un sitio a donde se llega con certezas.

Traducidos en Argentina apenas pocos años después, las escrituras de estos ensayos toman un curso distinto, menos relevante en relación con la influencia de Jean Paul Sartre y Lucien Goldman sobre el proceso de transformaciones críticas (Cella, Rosa, Capdevilla y Avaro) que cristalizó de alguna manera con el grupo Contorno. Una pregunta relevante es si acaso estas escrituras afectaron o intervinieron en un proceso de transformaciones críticas, y en tal caso cuáles fueron los modos de esa afección. Ésta sin embargo, no podrá ser respondida aquí, ya que debiéramos pensar primero dos problemas fundamentales que están en la base de esa inquietud: los vínculos con la historia, con la temporalidad de las escrituras, y el carácter tropológico, inasible de los ensayos de Georges Bataille y Maurice Blanchot. En los próximos apartados abordaremos esos dos problemas: por un lado, el lugar de estos textos particulares en la Historia de la Crítica en Argentina (Rosa 1999, 2003; Cella), que adquieren el carácter de restos de un archivo, más que la conformación de algún tipo de biblioteca teórica (Antelo 2015); y por el otro, señalar estos ensayos como episodios de resistencia a la teoría, en una doble acepción: resistencia de la literatura a ser conceptualizada y auto-resistencia de la escritura meta-literatura que advirtiendo el residuo de indeterminación que deja siempre el texto literario asume ella misma una sintaxis que desestabiliza la explicación gramatical y por tanto construye su forma de conceptualización como una instancia tropológica más (Paul De Man).

Pensar archivo y resistencia a la teoría como parte de un mismo problema es la entrada posible para leer estos ensayos en la dimensión temporal desfasada respecto de la periodicidad histórica que los hechos o las discursividades determinantes nos han marcado. Como restos críticos de una historia de nuestras lecturas, Bataille y Blanchot empujan, amenazan con desbaratar la consolidación de una mirada documentalista sobre la literatura porque señalan la imposibilidad de su concreción.

\section{Archivo de la crítica / Historia de la crítica: una superposición imperfecta}

La historia de la crítica literaria argentina ha reparado en dos ejes fundamentales para pensar el curso de sus escrituras y transformaciones: la política y la discursividad. Por un lado, Nicolás Rosa planteó que una historia de la crítica encuentra sus condiciones de legibilidad en la apelación a lo político; ${ }^{5}$ a partir de esa afirmación, organiza dos secuencias críticas historizables que van de Sarmiento a Viñas 
y de Prieto a Ludmer (Rosa 1999, 2003). Por otro lado, Susana Cella lee la crítica como la historia de una «irrupción» que se fecha a mediados de la década del 50 con la revista Contorno, pero se explica por la «eclosión discursiva» que producen diversas corrientes como el existencialismo, el marxismo, el psicoanálisis y el estructuralismo, en los modos de decir sobre literatura.

Esta trama histórica contiene o aloja una lectura de los años 50 caracterizados principalmente por la apropiación de Qu'est-ce que la littérature? (Sartre) por parte de David Viñas y Adolfo Prieto: política y productividad de un discurso teórico determinado confluyeron entonces en un programa intelectual definido e influyente para generaciones inmediatamente posteriores. El desplazamiento de una lectura filológica y estilística por una lectura materialista es sin dudas el cambio más notable y productivo en los modos de leer durante la década del 50. Analía Capdevilla y Nora Avaro han analizado bien cómo Contorno, al igual que Centro, fueron agentes de una transformación crítica que consistió entonces en abandonar el inmanentismo normativista y leer en cambio los modos en que lengua, literatura, tradición y poder fueron articulando conflictos y consensos (I2-I3).

Los ensayos de Bataille y Blanchot en Ciclo y Poesía Buenos Aires respectivamente son contemporáneos a esa «irrupción fechada». Pero estas escrituras no hallan lugar en la historización que organizan tanto Nicolás Rosa como Susana Cella, ya que no conforman ni una eclosión discursiva cuya productividad pueda rastrearse de manera manifiesta en otras escrituras locales, ni sus lecturas se vuelven imprescindibles para pensar el problema de la lengua y la tradición nacional.

La imposibilidad de pensar estos textos al resguardo de su época, pero especialmente la condición algo flotante o desarraigada en que circulaban por Argentina durante la década del 50 (y también en los 60), revela una experiencia de lectura mucho más inestable, reducida, y dispersa, que hoy incluso es difícil nominar como «crítica». Si Sartre y Goldman en el cruce entre humanismo y marxismo habían significado una influencia suficiente en escritores como David Viñas, Bataille y Blanchot demorarían algunas décadas en producir efectos críticos concretos en Argentina. La pregunta es, entonces, ¿cómo y dónde leer estos textos? Si no es deseable aplastar la potencialidad de esas escrituras transfiriendo las exigencias de la Historia para así reclamar su «injusto olvido», y en cambio preferimos apostar a su presencia indiferente, casi injustificada, es necesario recurrir a otro régimen que no es el de la historia ni el de las discursividades institucionales teóricas presentes.

Raúl Antelo en «La potencialidad del archivo» parte de una fotografía para pensar dos regímenes posibles, el del detalle, que correspondería al historiador que busca la razón de cada hallazgo, y el de archivo como "régimen centrífugo de evocaciones». No se trata de opuestos, sino de un archivo como superposición imperfecta, supernumeraria respecto de la Historia. La lógica por la cual un documento se suma, se pega o incluso superpone a otro en el archivo es únicamente la de la palabra — «figurar en el archivo no implica ni requiere ninguna etiqueta de nobleza» (Antelo 20I6) — . Esta distinción nos permite leer las escrituras de Bataille y Blanchot en Argentina en un espacio de posibilidad que no coincide 
con el que la Historia de la crítica ha tramado. Esa no-coincidencia, desplazamiento, superposición imperfecta, es la existencia simultánea de la Biblioteca (registro de la Historia) y el Archivo, de las lecturas que conformaron la sedimentación de sentidos y saberes en distintas secuencias críticas y lecturas inestables, difíciles de ubicar.

La relación entre teoría, crítica e historia en Argentina, parece más bien una cuestión de alojamiento, la existencia de un espacio disponible. En ese sentido, resulta pertinente o posible pensar estos textos y sus lecturas devenidas escrituras (Bayley, Molina, Pellegrini, Aguirre) como restos críticos de un archivo. No se trata de una historia-otra, sino de una superposición imperfecta: el archivo permite ver los restos de lo que no conformó «productividad en la historia» (Prieto 2006).

En «La potencialidad del archivo», Raúl Antelo, por un lado, apunta un «régimen de obra» capaz de ser leído o visualizado en formas de acercarse a la fotografía. Mientras «el historiador referencial cree poder activar en ellas el régimen del detalle», la visión que la máquina postula ("plétora de sentidos»/«saturación plástica mediada por la técnica») es para el archivista «un régimen centrífugo de evocaciones». Podríamos decir que el archivista, como obrador, suspende los criterios de selección y si se detiene en el detalle no es para extraerlo en su productividad histórica sino pensarlo en el haz de multiplicidades de lo que presenta.

El archivo deviene así, no tanto la memoria (materia acumulada) como el olvido del sentido simbólico de los materiales. Este olvido, agregaríamos, es el olvido de su «razón», de la justificación que explica la existencia de esos materiales en el archivo. Formular la pregunta ¿qué significan los textos de Georges Bataille y Maurice Blanchot entre 1948 y 1953 como traducciones inéditas en Argentina, en las revistas literarias?, supone, en principio, sustraerlos de la exigencia histórica, así como pensar una teoría literaria en los ańos 50 supone transpolar cortes históricos. Abrir un espacio en el archivo de la teoría y la crítica, no para contravencionar las lecturas, sino para pensar sus propios restos:

el saber existe [agrega Antelo citando a Foucault] para interrumpir la presión del pasado, y cuando esto sucede, lo que se obtiene no es la materialidad de nada acumulable, que pueda llamarse conocimiento, sino la disponibilidad de un espacio de experiencia, ahora totalmente abierto a la intervención arqueológica. (20I5:s/n)

Estos fragmentos exigen, en su condición de olvido, de existencia injustificada, su propia lectura, que sin dudas no es la que nos proporcionan herramientas tales como la discursividad productiva de la teoría o los anudamientos entre Historia y Política. No es casual que estos textos excéntricos y algo mudos en su época, para el campo cultural argentino, aparezcan, se nos presenten en revistas, donde se revela, las más de las veces, el cuerpo parcelado, fragmentado de la literatura, y se produce, por tanto, una lectura especular de los espacios negados. La revista, como la foto, puede mirarse en su régimen del detalle o en las evocaciones centrífugas de lo que arroja. ¿Cuál es, entonces, la "propia lectura» de estos ensayos 
para pensarlos en ese archivo de la crítica, convertidos en restos? La inestable gramática que aproxima y diluye la conceptualización.

\section{Auto-resistencia: la paradoja como tropos}

En «La resistencia a la teoría» Paul De Man hace una aclaración que nos interesa especialmente para pensar las escrituras de Bataille y Blanchot entre 1948 y I953. Por un lado, señala un corte cronológico preciso que le permitirá mostrar el caso, pero no el problema más general: la amenaza de la teoría se manifiesta en los años 6o, ya que entonces la lingüística es capaz de afirmar que «el nexo, la relación entre la palabra y la cosa no es fenoménica, sino convencional». Esto hace del lenguaje una materia epistemológicamente volátil y sospechosa, por lo cual la mímesis se vuelve un tropo más entre otros, y la condición tropológica del lenguaje se vuelve insoslayable. Si en los ańos 50 pudieron convivir perfectamente Curtius, Auerbach, Sartre, Croce y Spitzer, dice de De Man, fue a causa de que por teoría se entendiera «el enraizamiento de la exégesis literaria» (I5-I6). De Man identifica esta adversidad como «resistencia a la teoría», resistencia al uso del lenguaje sobre el lenguaje que desbarata un programa gramatical/pragmático cuya intención tiende hacia el dominio y el esclarecimiento del significado.

Por otro lado, la resistencia a la teoría resulta atemporal; Paul De Man advierte que si el ingreso de la lingüística a la teoría literaria y la consecuente resistencia que produce es una manifestación fechable, representa sólo un caso particular del problema que ha revelado:

[la] resistencia a la introducción de terminología lingüística en el discurso estético e histórico sobre la literatura, es sólo una versión particular de una cuestión que ya no se puede reducir a una situación histórica específica ni llamar moderna, postmoderna, romántica. (25)

La resistencia a la teoría pone de manifiesto el problema de que el lenguaje contenga pasajes de ningún modo agramaticales pero inútilmente explicables por la gramática. En ese sentido, los textos de Bataille y Blanchot son parte del problema con el cual la teoría y la crítica se han encontrado para escribir sobre literatura. «La moral de Henry Miller» $\mathrm{y}$ «René Char» suponen, en los años 50 en Argentina, un episodio de resistencia a la teoría, previo al momento de «eclosión discursiva» con el cual se pensó la historia de las transformaciones crítica y la renovación teórica en el país.

La noción de instante para Bataille, al igual que la idea de «conocimiento productivo de la realidad [por parte de la poesía]» para Blanchot, tienen un espesor ético y político definido, que asume un principio de incompletud en la experiencia de cualquier sujeto, y por tanto la imposibilidad de cualquier tipo de totalización, aunque no de su deseo. Esto tiene consecuencias precisas en una concepción del lenguaje que se vuelve tropológico, pues se trata del momento en el cual la teoría ya no explica nada acerca de la literatura (no hay exégesis ni hermenéutica). 
La más lejana verdad de Miller, ${ }^{6}$ dice Bataille, se podría expresar con esta fórmula: «Si no bajamos hasta lo más abyecto, si quedamos atados a la pureza del cielo perdemos por un engańo y para siempre el diamante del tiempo presente». En esa frase se conjugan dos de las obsesiones de Bataille: el bajo materialismo como salida al trascendentalismo idealista que encontraba en la apuesta del surrealismo por la escritura automática, y la política del instante ${ }^{7}$ —única totalidad posible — como política de la soberanía, capaz de negar la esclavitud de la acción. La fórmula de Bataille para pensar la literatura de Miller suspende la lógica y en cambio exhibe la retoricidad del lenguaje: allí donde la semántica opondría pureza a engaño, aquí se autoimplican, así como abyecto y diamante se corresponden, y esas díadas se diferencian en la estructura «si esto no lo otro». El diamante del presente se halla en la abyección, y en ese sentido será lo sagrado, mientras lo alto/puro/celeste es retirado de su posible condición de idealidad o trascendencia para empujarse a la esfera de lo engañoso.

Esa hipótesis de Bataille da lugar a la figura del monstruo y la noción de gasto. ${ }^{8}$ Pero ambas no se comprenden sin los alcances del presente como instante. Henry Miller ha rehusado la esclavitud de la acción perdurable a favor de la apuesta por el instante, "pero al rehusarla se rehúsa al mismo tiempo a lo posible: se acepta en contraposición el ser desgarrado, el quedarse apresado en lo imposible». Lo que aparece casi como un retruécano contiene en sí la paradoja: se ejerce la libertad total y con ella al mismo tiempo la imposibilidad que no es su reverso sino su parte la que inhibe una totalidad del ejercicio y por eso mismo da lugar a lo abierto. ${ }^{9}$

Rehusar la esclavitud de la acción práctica se presenta como la posibilidad de sustraerse a las palabras que construyen mundo justificando los fines útiles "por medio del pensamiento discursivo» (1948:30). Así, el discurso ordenado, la gramática, es la garantía de la instrumentalidad, mientras que el instante es la destrucción de la conciencia, el rechazo a la esclavitud de «lo que rinde», el lenguaje del «anonadamiento sin límites», lenguaje del último hombre, y por tanto el alojamiento de la imposibilidad. El instante es la discontinuidad, el punto, la interrupción en el curso de la necesidad que se manifiesta como discurso. Por eso, Bataille advierte, en su exposición de la lectura de Miller, un momento de límite que se manifiesta en un problema de lenguaje, aquello que es posible decir:

¿Sería posible dejar de expresar un anonadamiento sin límites cuando se lleva en sí el poder del instante? Ya no se puede entonces asociar la expresión literaria a lo perdurable sino a su contrario. Ni siquiera es importante que este mundo humano desaparezca de hecho. El instante aprehendido en su plenitud es, de todos modos, la ruina de las cosas ordenadas. Y el único lenguaje apropiado en tal caso sería el lenguaje del «último hombre»: sólo tiene sentido en la medida en que todo sentido se pierde, cambia las perspectivas a las que estamos acostumbrados y les sustituye una visión extática de una realidad que se nos escapa. (36) (cursiva mía)

Lo perdurable aquí es la discursividad que garantiza una conciencia, la idea de una relación estable o fenoménica, en términos demanianos, entre las palabras y las cosas; mientras el instante la aniquila, aniquila la referencia, por eso ya no im- 
portaría si el mundo humano desaparece, porque el instante prescinde del código que sostiene las correspondencias. Pero si en el poder del instante la expresión literaria es «momento eterno que destruye todos los valores, distancias o diferencias» (34), ¿cuál es su lenguaje?, ¿cuál es ese lenguaje del «último hombre»? Tal es la pregunta de Bataille que abre su lectura a la indeterminación del significado que comportan los textos de Miller.

El instante nos pone frente al corte de la discursividad, se trata de un punto que interrumpe la línea y evidencia su infinitud, pero este es imposible en tanto significado, es «sin límites», sólo tiene sentido si el sentido se pierde. Lenguaje del último hombre porque después de todo no habría continuidad, transmisión, perdurabilidad de esa expresión. Hasta aquí la cita presenta la dificultad para determinar y codificar la experiencia del instante según Bataille lee la secuencia de hechos que narra Miller, pero las oposiciones que se van señalando ordenan la argumentación. El problema se suscita cuando avanza hacia un posible esclarecimiento acerca de qué sería el lenguaje del instante o lenguaje del último hombre. Bataille afirma que este sería quien cambia nuestras perspectivas naturalizadas por "una visión extática de una realidad que se nos escapa».

La visión «extática» pone en el centro de nuestro problema la retoricidad del lenguaje. Mientras la conceptualización del término lo ha estabilizado como

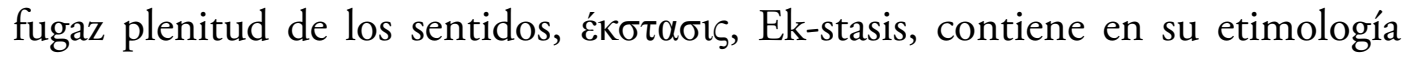

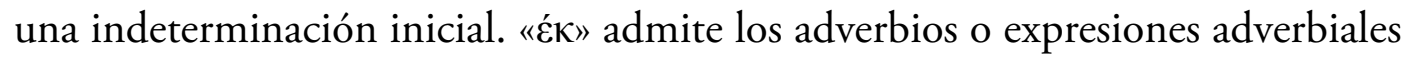

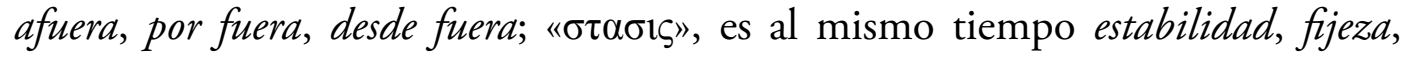
sitio y sublevación, revuelta, disensión, querella. ${ }^{10}$ Blanchot advierte esto sobre el pensamiento y la escritura de Bataille en los ańos 80, cuando vuelve a pensar la experiencia de Acépable en La comunidad inconfesable, entonces dice:

No hay que olvidar nunca que para él cuenta menos el estado de arrebato en que uno se olvida de todo (y de sí mismo) que el camino exigente que se afirma mediante la puesta en juego y la puesta fuera de sí de la existencia insuficiente, que no puede renunciar a esta insuficiencia, movimiento que arruina tanto la inmanencia como las formas habituales de la trascendencia. (...) Sólo se puede escribir esta palabra [éxtasis] poniéndola precavidamente entre comillas, porque nadie puede saber de qué se trata, y, ante todo, si ha tenido alguna vez lugar: al rebasar el saber, al implicar el no-saber, se rehúsa a ser afirmado de otro modo que mediante palabras aleatorias que no podrían garantizarlo. Su rasgo decisivo es que aquel que lo experimenta no está allí cuando lo experimenta, no está, pues, allí para experimentarlo. El mismo (pero no es el mismo) puede creer que recupera la posesión de sí en el pasado como un recuerdo: me recuerdo, me rememoro, hablo o escribo en el transporte que desborda y trastorna toda posibilidad de recordar. (2002:22)

«Extasis» es, entonces, al mismo tiempo el sitio y el afuera, la fijeza y la sublevación, por cuanto acontece para un sujeto que no está allí cuando acontece, por lo tanto es el mismo y otro. Ese instante que es sin límites para Bataille cambia la visión de las cosas a las que estamos acostumbrados por una visión extática, pero esta visión no tiene lugar, está fuera, es fijeza y revuelta, experiencia y desconoci- 
miento. La imposibilidad de renunciar a la insuficiencia que señala Blanchot tres décadas más tarde, es la imposibilidad de renunciar a lo imposible del instante que Bataille lee en la obra de Miller. La «sustitución» de la cual se nos habla en el párrafo de Bataille es el momento en el cual la escritura advierte que el lenguaje no explica nada acerca de aquello que ha encontrado como lo único de lo cual se quisiera hablar: el anonadamiento sin límites del poder del instante. La sustitución añora, desea, encontrar el nombre de aquello que reemplazaría «la visión de las cosas como estamos acostumbrados», pero tal experiencia ingresa como signo de lo perdurable en la relación entre la «expresión literaria» y el «mundo humano».

«[La literatura] nos pone también en relación con todo lo que en el mundo es soberanía, en oposición con todo lo que es hecho cumplido, pesadez del destino, petrificación del hombre», con esta afirmación, que bien podría ser atribuida a Bataille, Blanchot expone las ideas principales en torno a Hojas de Hipnos de René Char, en la exigencia de la política que entiende a su vez como exigencia impersonal en relación con la poesía.

Si en Bataille lo que llamamos resistencia de la literatura a ser conceptualizada y auto-resistencia de la propia escritura aparece con la figura del instante como insumisión de la literatura a los órdenes discursivos, el ensayo de Blanchot adopta la paradoja para pensar la relación entre poesía y realidad:

Bien se comprende cómo el horizonte de ausencia y de irrealidad que rodea al poema, la complacencia por lo imaginario y lo maravilloso, no significa sino uno de los términos de la contradicción poética fundamental: el poema va hacia la ausencia pero para recomponer con ella la realidad total; es tensión hacia lo imaginario, pero porque se propone «el conocimiento productivo de la realidad». La búsqueda de la totalidad, en todas sus formas, es la pretensión poética por excelencia, una pretensión en la cual está incluida, como su condición, la imposibilidad de su cumplimiento, de tal manera que, si alguna vez le ocurre cumplirse, es en tanto que esto no se pueda y porque el poema pretenda comprender en su existencia su imposibilidad y su irrealización. (1953:s/n)

La paradoja aparece aquí no sólo en la figura de la ausencia como aquello que recompone en lugar de retirarse, o bien, en la retirada suma el movimiento de alejarse. La paradoja radica también retóricamente en la determinación del posesivo «su cumplimiento» y aquello que se pretende; la pregunta sería si acaso es imposible el cumplimiento de la pretensión como acto, el mismo hecho de pretender, o si es imposible el cumplimiento del objeto de la pretensión. Blanchot dice "pretender la totalidad es imposible», pero el supuesto contexto/código de inferencias socialmente dado supone que la frase dice las dos cosas o las dos a la vez, o contiene lo que pragmáticamente determinamos (que lograr eso es imposible).

Las «notas de ese guerrillero» escritas en tensión, miedo, cólera, asco, ilusión, son simultáneamente lo "efímero del acontecimiento» y «lo que precede a toda calificación, escapa a toda determinación y no significa otra cosa que su propia imposibilidad». Pensar la política y la poesía como una exigencia de lo neutro, al 
igual que la relación entre realidad y poesía como paradoja de la ausencia, lo lleva a una teoría de la imagen. La imagen no radica en la asignación de un referente, no consiste en «una designación o una ilustración de las cosas y de los seres», no se trata de recuerdos personales o asociaciones objetivas, porque no está ligada a un lenguaje del que se puede tener clave, sino que es la ausencia de lo que ella nos da. Así, la poesía «sustituye sin cesar lo que muestra por lo que no puede ser mostrado, lo que dice por lo que no puede decirse»; la paradoja es la existencia de dos movimientos opuestos a la vez, donde nuevamente la idea de sustitución es lo imposible de determinar porque el código se ha retirado como reposo de los intercambios posibles.

Bataille y Blanchot exponen, en estos ensayos publicados tempranamente en Argentina, formas del pensamiento crítico para las cuales la historia y la estética se vuelven insuficientes ya que encuentran en su propio recorrido el problema de un lenguaje que no puede definir la experiencia del poema o del instante, en la escritura, sino en la errancia de aquello que designa.

\section{Conclusiones: resistencias y archivo}

En diciembre de 20I5, durante el workshop «Resistencias a la teoría», expuse un borrador de este trabajo, donde intentaba pensar si unos breves textos de Georges Bataille y Maurice Blanchot (pero también Jean Cocteau, René Char, Henry Miller) publicados en las revistas Ciclo, Poesía Buenos Aires y Letra y Linea entre I948 y I953, podían leerse como episodios de resistencias a la teoría aún previos a la «eclosión discursiva» de las teorías más importantes, tal como señala Susana Cella, y que coincide con el período delimitado por Paul De Man. Alberto Giordano, en una de sus intervenciones, habló del carácter de interés que debía suponer para el crítico la cuestión de la resistencia; es decir, ¿̨por qué nos interesa pensar y analizar episodios de la crítica literaria en Argentina que manifiestan la retoricidad del lenguaje, entendida esta como imposibilidad de determinación entre lógica y gramática? El riesgo, claro, es que todo pueda ser pensado bajo esa óptica, y por lo tanto, el posible interés se convierta en convención o protocolo de lectura.

Esa pregunta fue la que mantuve para pensar el hallazgo de estos textos de $\mathrm{Ba}$ taille y Blanchot en los ańos 50 en revistas argentinas cuyo impacto crítico en la Historia de la literatura parece, al menos, ser pasado por alto sin mayores dificultades. Esas escrituras, ya sea que se piensen en el programa general de las revistas o en el marco de discusión en torno al compromiso literario, continúan, de alguna manera, injustificadas, indiferentes a una razón por la cual pensarlas en una línea de lecturas decisivas generacionalmente para la crítica literaria argentina. Por este motivo, la resistencia a la teoría como problema con sus propios supuestos y posibilidades metodológicas, es decir, en términos de Paul De Man, «atemporal», "ahistórico», permitía pensar, con un régimen del archivo, el anacronismo de estos textos en su propia contemporaneidad. Y a su vez, se revelaba algo de la condición material de las revistas, como esa fotografía de evocaciones centrífugas que señala Antelo, donde el régimen del detalle que el historiador quisiera tomar para 


\section{dar cuenta de cada uno de sus elementos fracasa, y sólo queda pensar algunos de sus elementos en la indiferencia de la productividad, que es a la vez, la presencia perturbadora que impide cerrar las representaciones de una época.}

\section{Notas}

${ }^{1}$ Los primeros textos de Georges Bataille y Maurice Blanchot que circularon en Argentina traducidos aparecen en los años 6o, según leemos en las reseñas de Oscar del Barco para la revista Los Libros (1969-1976). Ya para entonces Noé Jitrik había publicado Horacio Quiroga. Una obra de experiencia y riesgo (1960), ensayo crítico que piensa con Blanchot el problema de la obra literaria.

${ }^{2}$ Un desarrollo más exhaustivo sobre el tema puede leerse en «Revistas de la vanguardia surrealista/invencionista y transformaciones de la crítica en los años 50", Revista de Literaturas Modernas, Universidad Nacional de Mendoza (Stedile Luna, en prensa).

3 Cfr.: «Les romans de Sartre» en La part du feu (Blanchot 1949).

${ }^{4}$ Años más tarde, en El espacio literario revisará las complejidades de la escritura automática, devolviéndole cierto espesor perdido por la extenuada recurrencia procedimental, y cuestionando fuertemente la idea del sueńo como acceso a una realidad inmediata, desujetada de las convenciones del mundo: «es natural que lo primero en aparecer en este encuentro de la poesía y de la escritura irreflexiva fuese la decisión de escapar de las coerciones: la razón nos vigila, el espíritu crítico nos retiene, hablamos según las conveniencias y las convenciones. La escritura automática no revela una posibilidad de escribir al margen de esos poderes, en el día, pero como desde afuera del día, de una manera nocturna, libre de lo cotidiano y de su mirada molesta. De allí que en la historia del surrealismo las libertades de escritura estén más ligadas a las «experiencias del dormir», sean una forma más apaciguada, menos arriesgada de estas experiencias. Cada uno de los amigos de Breton buscaba ingenuamente la noche en un dormir premeditado, cada uno se deslizaba fuera de su yo habitual y se creía más libre, dueño de un espacio más amplio. Esto dio lugar a desórdenes a los que hubo que poner fin por «elementales consideraciones de higiene mental» (2002:I6I).
${ }^{5}$ Lo político para Nicolás Rosa siempre es infranumerario en relación con la literatura; es decir, esta lo excede siempre, le sobra a la política, y en ese sentido la sutura con la historia no dejaría casi lugar para el acontecimiento.

${ }^{6}$ Miller será objeto de interés nuevamente en 1953 , en el primer número de Letra y línea, también dirigida por Aldo Pellegrini, cuya portada se inauguraba con una imagen de Robert Arlt. En esa oportunidad Pellegrini tradujo una carta a Michael Fraenkel sobre «el destino del hombre moderno» en la cual Miller postulaba una noción de tiempo e historia poco afable a una concepción de época como saber aprehensible. Podría leerse ese número I de Letra y línea como un desdoblamiento de la lectura batailleana: el monstruo ahora encarnado en la lectura de Alberto Vanasco sobre Roberto Arlt, y el debate sobre el presente como espacio imposible en una discusión más amplia sobre las posibilidades de construir una historia de la literatura argentina.

7 Silvio Mattoni afirma que la obra de Bataille es la escritura de un mismo instante: «la negación de aquella reducción de cada momento al siguiente que efectúa el mundo de la necesidad y de la acción» (I2).

${ }^{8}$ Cfr. de Bataille, «La noción de gasto» (en $\mathrm{N}^{\mathrm{o}} 7 \mathrm{de} \mathrm{La}$ critique sociale, enero de 1933) y La parte maldita [1949] (2009), Buenos Aires: Las Cuarenta.

9 Bataille cita a Miller en dos oportunidades sobre esta cuestión: «Quien conoce el sentido exacto de la libertad - libertad absoluta y no relativa - no puede dejar de reconocer que un instante como este es el mayor acercamiento a esa libertad que se puede alcanzar» (9), y «Escupir sobre el pasado no basta. Proclamar sobre el futuro no basta, se debe actuar como si el pasado estuviera muerto y el porvenir fuera irrealizable» (8).

10 Cfr. Diccionario manual griego. Griego clásicoespañol (2005). Madrid: vox. 


\section{Bibliografía}

antelo, raúl (2013). «La lectura poslógica de Ciclo», en Eduardo Becerra, coordinador. El surrealismo y sus derivas: visiones, declives y retornos. Madrid: Abada, I78-197.

(2015). «A potencialidade do arquivo». Traducción de Delfina Cabrera para el libro en preparación El archivo como política de lectura. Mimeo.

aVARo, NORA y ANALÍ́ CAPEDVILla (2004). Denuncialistas. Literatura y polémica en los so. Buenos Aires: Santiago Arcos.

BAYLEY, EDGAR (1945). «La batalla por la invención: manifiesto». Cuaderno Invención 2 [número único]. Buenos Aires.

bataille, georges [1946] (I948). «La moral de Henry Miller» en Ciclo I(I), 23-37. Traducción de Marcia Bastos [tal vez se trate de un seudónimo].

(2008). «¿Es útil la literatura?», «La felicidad, el erotismo y la literatura», "Carta a René Char sobre las incompatibilidades del escritor» $\mathrm{y}$ «Sociología». La felicidad, el erotismo y la literatura. Ensayos 1944-I96r. Buenos Aires: Adriana Hidalgo. Traducción de Silvio Mattoni.

(2005). «El monstruo», «Nietzche y los fascistas», «La práctica de la alegría frente a la muerte». Acéphale. Buenos Aires: Caja Negra, 26-29, 35-57, 163-170.

BATAILlE, GEORGES Y MICHEL LEIRIS (2008). Intercambios y correspondencias. 1924-1982. Buenos Aires: El cuenco de plata. Traducción de Silvio Mattoni.

BLANChOt, MAURICE (1949). «La literatura y el derecho a la muerte». La parte de fuego. Madrid: Arena Libro, 2007, 269-303. Traducción de Isidro Herrera.

(I953). «Rene Char». poesía buenos aires, II/I2 (3), I34-I36, 20I4. Edición facsimilar. Traducción s/n.

(1983). La comunidad inconfesable. Madrid: Editora Nacional, 2002. Traducción de Isidro Herrera.

(2002). El espacio literario. Madrid: Editora Nacional. Traducción de Vicky Palant y Jorge Jinkis.

CELla, susana (1999). "La irrupción de la crítica» y "Panorama de la crítica», en Noé Jitrik, director. Historia critica de la literatura argentina, La irrupción de la crítica, en Susana Cella, directora del volumen io. Buenos Aires: Emecé, 7-16, 33-62.

DE MAN, PAUL (1986). «La resistencia a la teoría». La resistencia a la teoría. Madrid: Visor, 1990. Traducción de Elena Elorriaga y Oriol Francés.

MATtoni, silvio (2008). "Prólogo. La lucidez y el deslumbramiento», en Georges Bataille. La felicidad, el erotismo y la literatura. Ensayos 1944-I96I. Buenos Aires: Adriana Hidalgo, 7-I3. Traducción de Silvio Mattoni.

PRIETO, MARTín (2006). Breve historia de la literatura argentina. Buenos Aires: Taurus.

ROSA, NICOLÁs (1999). «Introducción. Hipótesis sobre la relación entre la historia y la literatura argentina», "Veinte años después o la "novela familiar" de la crítica literaria», en Nicolás Rosa, editor. Políticas de la crítica. Historia de la crítica literaria en la Argentina. Buenos Aires: Biblos, 9-20, 32I-348.

(2003). La letra argentina. Crítica 1970-2002. Buenos Aires: Santiago Arcos. SARTRE, JEAN PAUL (1948). Qu'est-ce que la littérature? París: Gallimard. 